\title{
PVA-PSSA Membrane with Interpenetrating Networks and its Methanol Crossover Mitigating Effect in DMFCs
}

\author{
A. K. Sahu, ${ }^{a}$ G. Selvarani, ${ }^{a}$ S. Pitchumani, ${ }^{a}$ P. Sridhar, ${ }^{a, *}$ A. K. Shukla,,${ }^{a, b, *, z}$ \\ N. Narayanan, ${ }^{\mathrm{c}}$ A. Banerjee, ${ }^{\mathrm{c}}$ and N. Chandrakumar ${ }^{\mathrm{c}}$ \\ ${ }^{a}$ Central Electrochemical Research Institute, Karaikudi 630 006, India \\ ${ }^{b}$ Solid State and Structural Chemistry Unit, Indian Institute of Science, Bangalore 560 012, India \\ ${ }^{c}$ Department of Chemistry, Indian Institute of Technology Madras, Chennai 600 036, India
}

\begin{abstract}
A membrane with interpenetrating networks between poly(vinyl alcohol) (PVA) and poly(styrene sulfonic acid) (PSSA) coupled with a high proton conductivity is realized and evaluated as a proton exchange membrane electrolyte for a direct methanol fuel cell (DMFC). Its reduced methanol permeability and improved performance in DMFCs suggest the new blend as an alternative membrane to Nafion membranes. The membrane has been characterized by powder X-ray diffraction, scanning electron microscopy, time-modulated differential scanning calorimetry, and thermogravimetric analysis in conjunction with its mechanical strength. The maximum proton conductivity of $3.3 \times 10^{-2} \mathrm{~S} / \mathrm{cm}$ for the PVA-PSSA blend membrane is observed at $373 \mathrm{~K}$. From nuclear magnetic resonance imaging and volume localized spectroscopy experiments, the PVA-PSSA membrane has been found to exhibit a promising methanol impermeability, in DMFCs. On evaluating its utility in a DMFC, it has been found that a peak power density of $90 \mathrm{~mW} / \mathrm{cm}^{2}$ at a load current density of $320 \mathrm{~mA} / \mathrm{cm}^{2}$ is achieved with the PVA-PSSA membrane compared to a peak power density of $75 \mathrm{~mW} / \mathrm{cm}^{2}$ at a load current density of $250 \mathrm{~mA} / \mathrm{cm}^{2}$ achievable for a DMFC employing Nafion membrane electrolyte while operating under identical conditions; this is attributed primarily to the methanol crossover mitigating property of the PVA-PSSA membrane.
\end{abstract}

(C) 2008 The Electrochemical Society. [DOI: 10.1149/1.2912040] All rights reserved.

Manuscript submitted December 10, 2007; revised manuscript received March 24, 2008. Available electronically May 5, 2008.

Direct methanol fuel cells (DMFCs) using a proton exchange membrane have been identified as one of the most promising candidates for portable power applications. ${ }^{1,2}$ Unlike hydrogen-air polymer electrolyte fuel cells, DMFCs do not require a fuel reformer or a high-volume hydrogen storage system. The membrane electrolyte employed with the DMFC, besides exhibiting a good proton conductivity, should act as a physical separator to prevent fuel crossover from the anode to the cathode. At present, Nafion a perfluorosulfonated membrane with a hydrophobic fluorocarbon backbone and hydrophilic sulfonic acid pendant side chains, happens to be the only commercially available and widely used membrane electrolyte in the DMFC. It has been documented that proton conduction in Nafion occurs through the ionic channels formed by micro- or nanophase separation between the hydrophilic proton exchange sites and the hydrophobic domains. ${ }^{3}$ However, the methanol crossover from anode to cathode across the Nafion membrane brings about a mixed potential at the cathode causing both the loss of fuel and cell polarization impeding their commercial realization. ${ }^{4-6}$ It has been reported that even over $40 \%$ of methanol could be lost in a DMFC due to crossover across the membrane. ${ }^{7}$ Methanol crossover across the Nafion membrane can be kept to a minimum by controlling the methanol-feed concentration. Alternatively, membranes that are relatively impermeable to methanol have been employed for this purpose. ${ }^{8-12}$ Membranes with a lower methanol permeability allow a higher methanol-feed concentration, enhancing the performance of the DMFC. To optimize fuel cell performance, it is necessary to understand the nature of the methanol transport processes within and across the membrane. For a high-performance DMFC, undesirable methanol crossover through the membrane electrolyte should be reduced while maintaining its excellent proton conductivity and mechanical stability.

Proton conductivity is only a part of the puzzle. The material must be manufacturable as also processable into thin sheets for low resistance. It must be compatible with the electrodes and possess a form suitable for electrode/membrane bonding to avoid losses due to interfacial resistance. It should be chemically, thermally, and dimensionally stable, impervious to reactant gases or liquid fuels, and should be electrically insulating. Accordingly, efforts to develop alternative membranes need to address these issues.

* Electrochemical Society Active Member

z E-mail: shukla@sscu.iisc.ernet.in
To this end, suitably modified Nafion composite membranes with inorganic fillers such as silica, titania, zirconia, etc. have been widely investigated..$^{8-10,13-16}$ The addition of inorganic fillers narrows the hydrophilic channels in the Nafion from 7.9 to $6.5 \mathrm{~nm}$, facilitating proton conduction. Besides, the filler particles inhibit the permeation of methanol through the membrane that leads to performance improvement in DMFCs. However, during the composite preparation, either by physical mixing or by the wet-chemical approach, there is always a possibility of membrane heterogeneity. Both the lack of interaction between fillers and Nafion in the case of lower loading levels as well as any excess of the inorganic phase could impede proton conduction in the membrane by disrupting the continuity of the proton conduction path in the Nafion matrix.

Poly(vinyl alcohol) (PVA) is a cheap and attractive material for preparing electrolyte membrane due to its good mechanical and chemical stability. ${ }^{17}$ Under acidic conditions, the $-\mathrm{OH}$ groups of PVA have the tendency to chemically cross-link with aldehydes to form acetal or hemiacetal linkages. ${ }^{18}$ The PVA membrane itself does not have any negatively charged ions and hence is a poor proton conductor as compared with the commercially available Nafion membrane. However, several organic groups like hydroxyl, amine, carboxylate, sulfonate, phenolic, and quaternary ammonium salts can be incorporated into PVA to enhance its proton conductivity and hydrophilicity. ${ }^{19-21}$

Li et al. ${ }^{22}$ have realized PVA membranes doped with phosphotungstic acid (PWA). However, the excessive swelling of a PVAPWA composite membrane limits its mechanical strength. Xu et al. ${ }^{23}$ have incorporated silica particles into a PVA-PWA composite membrane with improved endurance and thermal stability. Recently, Rhim et al. ${ }^{24}$ reported PVA cross-linked with sulfosuccinic acid (SSA), a proton-conducting material. After optimizing the degree of cross-linking and associated temperature, the maximum proton conductivity for the PVA-SSA membrane is found to be between $10^{-3}$ and $10^{-2} \mathrm{~S} / \mathrm{cm}$. As an extension, Kim et al. ${ }^{25}$ fabricated a PVASSA-silica hybrid membrane, using a sol-gel route, that exhibits a good proton conductivity even at elevated temperatures. Wu et al. ${ }^{26}$ prepared an alkaline PVA-poly(acrylic acid) (PVA-PAA) composite membrane with varying PAA content. It was found that the PVAPAA composite membrane at the respective composition ratio of 10:5 shows a good balance in proton conductivity and mechanical properties. Recently, Kim et al. ${ }^{27}$ reported the preparation of a PVApoly(styrene sulfonic acid-co-maleic acid) (PVA-PSSA-MA) polymer electrolyte membrane. The composite membrane controls the 
membrane charge density and also prevents excessive swelling while exhibiting good proton conductivity of $\sim 10^{-2} \mathrm{~S} / \mathrm{cm}$ at room temperature.

It is in this context that the present investigation has identified a poly(vinyl alcohol)-based membrane with two different types of proton conduction in a tailor-made entity comprising both PVA and PSSA moieties to mimic Nafion-like properties for fuel cell operation. Following its accidental discovery by Haehnel and Herrmann in 1924, PVA has become one of the most studied polymers. ${ }^{28-33}$ PVA can be industrially produced rather cheaply; it is nontoxic and can easily form thin, large surface-area membranes, a characteristic most desired of fuel cells. We have characterized the PVA-PSSA membrane with interpenetrating networks developed during this study by various nuclear magnetic resonance (NMR) techniques including imaging, ${ }^{34}$ volume localized spectroscopy, and diffusometry. These are powerful techniques to investigate water and methanol dynamics in and across the membrane material.

Methanol self-diffusion coefficients, as determined by NMR techniques, are contrasted with methanol release kinetics NMR measurements; the former helps investigate localized environments and is sensitive to chemical composition and morphology, while the latter provides insight into the averaged long-range methanol transport properties. This contrast provides a bridge between the fundamental understanding of the composition and morphological structure of the membrane, and the impact of these factors on transport and the application of these membranes in DMFC technology. Indeed, spatially resolved NMR appears to emerge as an important tool in designing and identifying a membrane electrolyte for fuel cell applications.

We report the effective utility of a PVA-PSSA membrane in DMFCs. Such a DMFC yields a maximum power density of $90 \mathrm{~mW} / \mathrm{cm}^{2}$ at a load current density of $320 \mathrm{~mA} / \mathrm{cm}^{2}$ while operating at $70^{\circ} \mathrm{C}$ with $2 \mathrm{M}$ aqueous $\mathrm{CH}_{3} \mathrm{OH}$ and gaseous oxygen feeds at its anode and cathode, respectively. The study also provides a diagnostic route for designing alternative membranes for fuel cells.

\section{Experimental}

PVA [99.7\% hydrolyzed; molecular weight (Mw) 115,000; Loba Chemie, India], poly(sodium-poly-styrene sulfonate) (Acros Organics; Mw 70,000), glutaraldehyde (25\% aqueous), and sulfuric acid (98\%) (both obtained from S. D. Fine Chemicals, India), as well as solvents were used as received. Deionized (DI) water $(18.4 \mathrm{M} \Omega \mathrm{cm}$ ) used for experiments was produced by a Millipore system.

Next, $100 \mathrm{~mL}$ of $10 \mathrm{wt} \%$ PVA aqueous solution was prepared by dissolving the preweighed amount of PVA in water at $90^{\circ} \mathrm{C}$, followed by its stirring for about $3 \mathrm{~h}$ to obtain a clear solution. The solution thus obtained was allowed to cool to room temperature. Then, $2 \mathrm{~mL}$ of glutaraldehyde (GA) solution was added gradually, followed by its stirring for 3-4 h. The required amount of poly(sodium-poly-styrene sulfonate) dissolved in water was added to the resultant PVA solution. The resultant mixture was stirred at room temperature until a homogeneous slurry was obtained. The resulting slurry is referred to as PVA-PSSA blend solution. The slurry was then cast as a membrane on a flat Plexiglas plate and allowed to dry at $60^{\circ} \mathrm{C}$ in a forced air convection oven. The PVA and PVA-PSSA blend membranes thus formed were removed and further cross-linked chemically by dipping in $2 \mathrm{M}$ aqueous $\mathrm{H}_{2} \mathrm{SO}_{4}$ solution for $3 \mathrm{~h}$ at room temperature $\left(\sim 30^{\circ} \mathrm{C}\right)$. This process also facilitated the exchange of $\mathrm{Na}^{+}$ions present in the blend membrane with $\mathrm{H}^{+}$ions. After the reaction, the membranes were taken out and washed copiously with DI water to expel residual $\mathrm{H}_{2} \mathrm{SO}_{4} \cdot{ }^{35}$ All the membranes were stored in water for later use. The thickness of all the resultant membranes was around $150 \mu \mathrm{m}$.

The crystalline structure of the membranes was examined using a Philips X-Pert X-ray diffractometer with a $\mathrm{Cu} \mathrm{K} \alpha$ radiation of wavelength $\lambda=1.54 \AA$. The surface morphology was examined by a JEOL JSM 5400 scanning electron microscope (SEM). Thermo- gravimetric analysis (TGA) was carried out using an SDT Q600 V8.2 TGA instrument, U.S.A. The measurements were made from 298 to $923 \mathrm{~K}$, at a heating rate of $10^{\circ} \mathrm{C} /$ min under a $\mathrm{N}_{2}$ atmosphere. The thermal characterization of pristine PVA and PVA-PSSA electrolyte membranes was conducted using a Mettler Toledo DSC825e temperature-modulated differential scanning calorimeter (DSC) between 303 and $473 \mathrm{~K}$ facilitated with Toledo Performance Evaluation Method (TOPEM) software. The mechanical strength, based on the ASTM D 882 constant rate of grip separation test, was evaluated from the stress-strain test on a Shimadzu universal testing instrument Autograph AGS-J $10 \mathrm{kN}$ at $30^{\circ} \mathrm{C}$. Membranes were pulled at a crosshead speed of $1 \mathrm{~mm} / \mathrm{min}$.

The water uptake of PVA and PVA-PSSA blend membranes was measured by immersing the membrane samples into DI water at room temperature for $24 \mathrm{~h}$. Subsequently, the membranes were taken out, wiped carefully with a tissue paper, and immediately weighed on a microbalance. After drying the samples overnight in an air oven at $80^{\circ} \mathrm{C}$, they were weighed again; the water uptake in the membranes, $W$, was obtained from the expression

$$
W=\frac{W_{\text {wet }}-W_{\text {dry }}}{W_{\text {dry }}}
$$

where $W_{\text {dry }}$ and $W_{\text {wet }}$ are the weight of dry and corresponding watersorbed membranes, respectively.

Proton conductivity measurements were performed on the membranes in a two-probe cell using the ac impedance technique. The conductivity cell was comprised of two stainless steel electrodes, each of $20 \mathrm{~mm}$ diameter. The membrane sample was sandwiched in between these two stainless steel electrodes fixed in a Teflon block and kept in a closed glass container. The ionic conductivity data for the membranes were obtained under fully humidified conditions $(\sim 100 \%)$ by keeping DI water at the bottom of the test container and equilibrating for around $24 \mathrm{~h}$. Subsequently, the measurements were conducted between 303 and $403 \mathrm{~K}$ in the glass container having a provision for heat. The temperature was constantly monitored with a thermometer kept inside adjacent to the membrane. AC impedance spectra of the membranes were recorded in the frequency range between $1 \mathrm{MHz}$ and $10 \mathrm{~Hz}$ with $10 \mathrm{mV}$ amplitude using an Autolab PGSTAT 30 instrument. The resistance value associated with the membrane conductivity was determined from the highfrequency intercept of the impedance with the real axis. The membrane conductivity was calculated from the membrane resistance, $R$, from the equation

$$
\sigma=\frac{l}{R A}
$$

where $\sigma$ is the proton conductivity of the membrane $(\mathrm{S} / \mathrm{cm}), l$ is the membrane thickness (in centimeters), and $A$ is the cross-sectional area of the membrane samples (in $\mathrm{cm}^{2}$ ).

For measurement of methanol crossover across the membranes, experiments were carried out in a two-compartment glass cell with the membrane in between. The aqueous $2 \mathrm{M}$ methanol solution mixed with $0.5 \mathrm{M} \mathrm{H}_{2} \mathrm{SO}_{4}$ was introduced on the left side (chamber 1) of the two-compartment cell, and $0.5 \mathrm{M} \mathrm{H}_{2} \mathrm{SO}_{4}$ solution was placed on the right side (chamber 2). Methanol permeates from chamber 1 to chamber 2 through the membrane. Smooth platinum electrodes were used as the working and counter electrodes. A $\mathrm{Hg} \mid \mathrm{Hg}_{2} \mathrm{SO}_{4}, \mathrm{SO}_{4}^{2-}$ (MMS) reference electrode was used throughout. Cyclic voltammograms (CVs) were recorded using a SOLARTRON analytical 1480 Multistat to qualitatively estimate the methanol permeability of the membrane. The initial voltage and the potential steps were, respectively, 0 and $0.3 \mathrm{mV}$ vs MMS. The results were taken at $1 \mathrm{~h}$ intervals and final data were recorded after reaching equilibrium at around $5 \mathrm{~h}$. The amount of methanol permeating through the membrane was calculated from the methanol oxidation currents observed in the CVs.

The self-diffusion coefficient of water absorbed in the membranes was determined by the NMR pulsed field gradient stimulated 
echo (PGSTE) technique. ${ }^{36}$ The experiment was carried out on a Bruker $500 \mathrm{MHz}$ wide-bore Avance II NMR system equipped with a $5 \mathrm{~mm}$ diffusion probe, permitting a maximum $z$-gradient amplitude of about $18 \mathrm{~T} \mathrm{~m}^{-1}$. The sample in each case was a piece of the membrane (ca. $4 \mathrm{~mm} \times 4 \mathrm{~mm} \times 150 \mu \mathrm{m}$ ) saturated with water and surface blotted. A set of experiments was carried out separately for PVA, PVA-PSSA (25 wt \%) blend membranes, as well as for Nafion-117, all at $25^{\circ} \mathrm{C}$. The relevant experimental parameters were spectral width $=100,000 \mathrm{~Hz}$; relaxation delay $=5 \mathrm{~s}$; number of time domain data points $=1024$; number of scans $=4$. The diffusion experiment was performed as a function of gradient amplitude. The fit equation employed to obtain the diffusion coefficient $D$ was

$$
I(g)=I(0) \exp \left[-D \gamma^{2} g^{2} \delta^{2}\left(\Delta-\frac{\delta}{3}\right)\right]
$$

where $I(g)$ is the signal intensity that results for a gradient amplitude $g, I(0)$ is the signal intensity that results when the gradient is off, $\gamma$ is the magnetogyric ratio of the observed nucleus, $\delta$ is the gradient pulse duration $(1 \mathrm{~ms})$, and $\Delta$ is the time interval between the start of the two gradient pulses $(5.78-70 \mathrm{~ms})$ that encode and decode the diffusion.

Echo planar imaging-based diffusion maps ${ }^{37}$ of the membranes (ca. $3 \mathrm{~cm} \times 2 \mathrm{~cm} \times 150 \mu \mathrm{m}$ ) were also generated based on the pulsed gradient spin echo method ${ }^{38}$ at $200 \mathrm{MHz}$ on a Bruker Biospec 47/40 USR system to obtain the apparent diffusion coefficients (ADCs) in chosen regions of interest employing coronal (ZX) images. The experiments were performed with a $112 / 72 \mathrm{~mm}$ resonator in an actively shielded $12 \mathrm{~cm}$ gradient insert. ADCs were thus obtained for water in $2 \mathrm{M}$ methanol/water, and $\mathrm{CH}_{3} \mathrm{OH}$ in $2 \mathrm{M}$ methanol/ $\mathrm{D}_{2} \mathrm{O}$ using membranes equilibrated in the respective solvent/solvents mixtures.

Methanol release studies were also undertaken. Here, the diffusion of methanol from membrane balls saturated with $2 \mathrm{M}$ methanol in $\mathrm{D}_{2} \mathrm{O}$ into a surrounding medium of $2 \mathrm{M} \mathrm{CD}_{3} \mathrm{OD}$ in $\mathrm{H}_{2} \mathrm{O}$ was investigated. The experimental strategy was to acquire the volume localized high-resolution proton $\left({ }^{1} \mathrm{H}\right)$ NMR spectrum from a volume element in the surrounding medium outside the membrane ball as a function of time; the voxel chosen was a cube of edge $4 \mathrm{~mm}$. The volume localization protocol employed was point resolved spectroscopy (PRESS), ${ }^{39,40}$ other relevant experimental parameters being repetition time $(\mathrm{TR}=2500 \mathrm{~ms}(1000 \mathrm{~ms}$ for Nafion), echo time $(\mathrm{TE})=13.408 \mathrm{~ms}$, and number of averages $(\mathrm{NA})=64$.

The membranes were used for their performance evaluation in DMFC by making membrane electrode assemblies (MEAs). An MEA consists of a membrane sandwiched between an anode and a cathode. Both the anode and cathode are comprised of a backing layer, a gas-diffusion layer (GDL), and a reaction layer. Teflonized Toray carbon papers (thickness $=0.27 \mathrm{~mm}$ ) were employed as the backing layers in these electrodes. Diffusion layers comprised of $1.5 \mathrm{mg} / \mathrm{cm}^{2}$ of Vulcan XC-72R carbon slurry dispersed in cyclohexane were applied onto the backing layers and sintered in a muffle furnace at $350^{\circ} \mathrm{C}$ for $30 \mathrm{~min}$. Pt-Ru (60 wt \%, 1:1 atomic ratio), supported on Vulcan XC-72R carbon (Johnson Mathey) mixed with binder and coated onto one of the GDLs, represented the catalyst layer on the anode, and 40 wt \% Pt catalyst supported on Vulcan $\mathrm{XC}-72 \mathrm{R}$ carbon $^{5}$ (in-house) mixed with binder coated onto the other GDL represented the catalyst layer on the cathode. The binder was Nafion solution for MEAs with Nafion-117 membrane, PVA solution for MEAs with PVA membrane, and PVA-PSSA solution for MEAs with PVA-PSSA membrane. The catalyst loading on both the anode and cathode was kept at $2 \mathrm{mg} / \mathrm{cm}^{2}$. A thin layer of Nafion solution was subsequently applied over the catalyst layer for fabricating the MEA using Nafion-117 membrane. Similarly, a thin layer of PVA solution was applied over the catalyst layer of each electrode for MEA with the PVA membrane and a thin layer of PVA-PSSA solution was applied onto the catalyst layer of each electrode for MEA with the PVA-PSSA membrane. The active area for the DMFCs was
$4 \mathrm{~cm}^{2}$. MEAs with PVA and PVA-PSSA blend membranes were obtained by hot-pressing at $15 \mathrm{kN}\left(\sim 60 \mathrm{~kg} / \mathrm{cm}^{2}\right)$ at $80^{\circ} \mathrm{C}$ for 3 min. The MEA with the Nafion-117 membrane was hot-pressed at $125^{\circ} \mathrm{C}$ for $3 \mathrm{~min}$.

MEA performance was evaluated using a conventional fuel cell fixture with a parallel serpentine flow field machined on graphite plates (Schunk Kohlenstofftechnic). The cells were tested at $70^{\circ} \mathrm{C}$ with $2 \mathrm{M}$ aqueous methanol with a flow rate of $4 \mathrm{~mL} / \mathrm{min}$ at the anode side and oxygen at the cathode side with a flow rate of 400 sccm per minute at atmospheric pressure. Measurements of the cell potential as a function of current density were conducted galvanostatically using an LCN100-36 electronic load (Bitrode Corporation, U.S.A.). In situ measurements on $\mathrm{CO}_{2}$ permeation and methanol crossover from anode to cathode for different membranes in the fuel cell have been carried out as reported in the literature. ${ }^{41}$ In brief, the methanol crosses over from the anode to the cathode through the polymer electrolyte membrane in DMFC. At the cathode, the crossed-over methanol from the anode is oxidized catalytically by a reaction with oxygen at the catalyst surface. The amount of crossedover methanol can be analyzed gravimetrically by monitoring the $\mathrm{CO}_{2}$ at the cathode exhausts. For this purpose, $\mathrm{CO}_{2}$ from the cathode outlet was passed through a clear but saturated $\mathrm{Ba}(\mathrm{OH})_{2}$ solution, which leads to the formation of $\mathrm{BaCO}_{3}$ precipitate according to Eq. 4

$$
\mathrm{CO}_{2}+\mathrm{Ba}(\mathrm{OH})_{2} \rightarrow \mathrm{BaCO}_{3} \downarrow+\mathrm{H}_{2} \mathrm{O}
$$

$\mathrm{BaCO}_{3}$ precipitate was separated from the liquid by a centrifuge, washed with DI water, and subsequently dried at $70^{\circ} \mathrm{C}$ for $24 \mathrm{~h}$. After cooling to room temperature, it was weighed in a precision balance. The transport of methanol in a DMFC can be visualized in terms of equivalent currents to obtain the rates of methanol crossover. The equivalent current $\left(i_{\mathrm{pmtMeOH}}, \mathrm{mA} / \mathrm{cm}^{2}\right)$ of the crossedover methanol from the anode to the cathode can be described as follows

$$
i_{\text {pmtMeOH }}=\frac{6 F\left(W_{\mathrm{BaCO}_{3}}\right)_{\mathrm{c}}}{3600 A M_{\mathrm{BaCO}_{3}}}
$$

The term on the right side of Eq. 5 expresses the equivalent current of total $\mathrm{CO}_{2}$ flux collected at the cathode exhaust, $F$ represents the Faraday constant, $\left(W_{\mathrm{BaCO}_{3}}\right)_{\mathrm{c}}$ is the dry $\mathrm{BaCO}_{3}$ weight collected at the cathode exhaust in $1 \mathrm{~h}(\mathrm{mg} / \mathrm{h}), A$ is the electrode area $\left(\mathrm{cm}^{2}\right)$ of the cell, and $M_{\mathrm{BaCO}_{3}}$ is the molecular weight of $\mathrm{BaCO}_{3}$. The aforesaid procedure was repeated at different load current densities and the corresponding equivalent currents $\left(i_{\mathrm{pmtMeOH}}, \mathrm{mA} / \mathrm{cm}^{2}\right)$ of the crossed-over methanol were estimated.

\section{Results and Discussion}

$X R D$ analysis. - The interpenetrating networks in PVA-PSSA blend membranes in conjunction with GA are shown in Fig. 1. Figure 2 shows X-ray diffraction (XRD) patterns for pristine PVA and PVA-PSSA blend membranes. As reported by Xu et al., ${ }^{23}$ the PVA membrane shows a semicrystalline structure with a distinct peak at $2 \theta \approx 20^{\circ}$ and a broad peak at $2 \theta \approx 41^{\circ}$. The intensity of the peak at $20^{\circ}$ decreases dramatically as the PSSA content increases in the PVA-PSSA blend membrane, and the amorphous region in PVAPSSA blend membrane appears more pronounced. The amorphous characteristic of the PVA-PSSA blend membrane seen here helps enhance the ionic conductivity due to the flexibility of local chain segmental motion in the polymer matrix. ${ }^{42}$

Electron microscopy results.- Figure 3 illustrates typical SEM pictures for pristine PVA and PVA-PSSA blend membranes. In the micrographs, the PVA-PSSA blend membrane shows a lesser surface homogeneity with extended roughness in relation to a pristine PVA membrane. It is noteworthy that the membrane roughness is beneficial for promoting liquid permeation in the membrane and water retention. 
<smiles>CCC(O)CC(C)(C)C</smiles><smiles>O=CCC=O</smiles><smiles>CCC(O)CC(O)C(C)(C)C</smiles>

PVA - GA

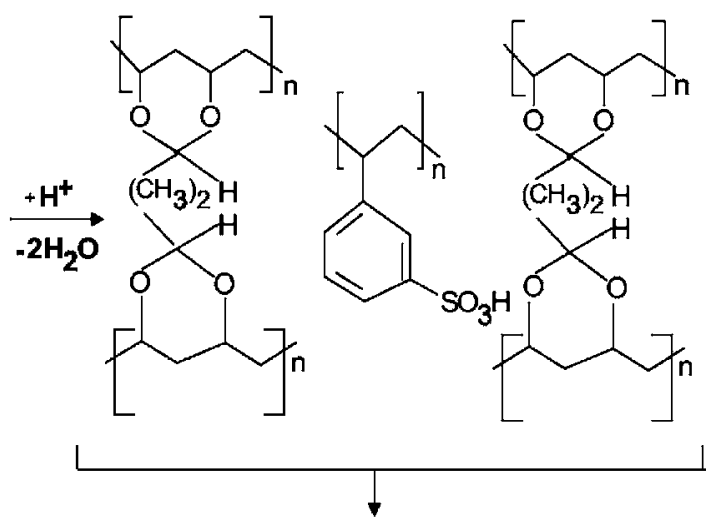

PVA - PSSA Interpenetrating Network
Figure 1. Interpenetrating networks of PVA-PSSA polymer in conjunction with GA.
TGA and DSC study.- As shown in Fig. 4, TGA curves of the PVA-PSSA blend membranes are fitted using three main degradation stages arising from thermal dehydration, thermal desulfonation, and thermal oxidation of the polymer matrix. The first weight loss of 30 wt $\%$ between $\sim 303$ and $\sim 453 \mathrm{~K}$ is due to the evaporation of surface and moderately bound water in the blend membranes. By comparison, a weight loss of only about $10 \mathrm{wt} \%$ is seen for the pristine PVA membrane between $\sim 303$ and $\sim 423 \mathrm{~K}$. The second weight loss of about $10 \mathrm{wt} \%$ for PVA-PSSA membranes is found between $\sim 453$ and $693 \mathrm{~K}$, and corresponds to the loss of sulfonic acid groups by desulfonation; there is no such weight loss seen for pristine PVA membrane due to the absence of sulfonic acid groups. In the third weight loss region at temperatures $>693 \mathrm{~K}$, the polymer residues are further degraded at $T=743 \mathrm{~K}$, which corresponds to the decomposition of the main chains of the PVA. ${ }^{27}$ By comparison, the PVA membrane undergoes total thermal oxidation between $\sim 423$ and $\sim 743 \mathrm{~K}$ due to the decomposition of its polymeric (side and main) chains. ${ }^{43}$ The remaining mass after the polymer decomposition in all the membranes is due to the residual char.

Figure 5 shows the DSC-TOPEM data for pristine PVA and PVA-PSSA membranes. The reversing heat flow curves are considered for calculation of the glass transition temperature $\left(T_{\mathrm{g}}\right)$. The

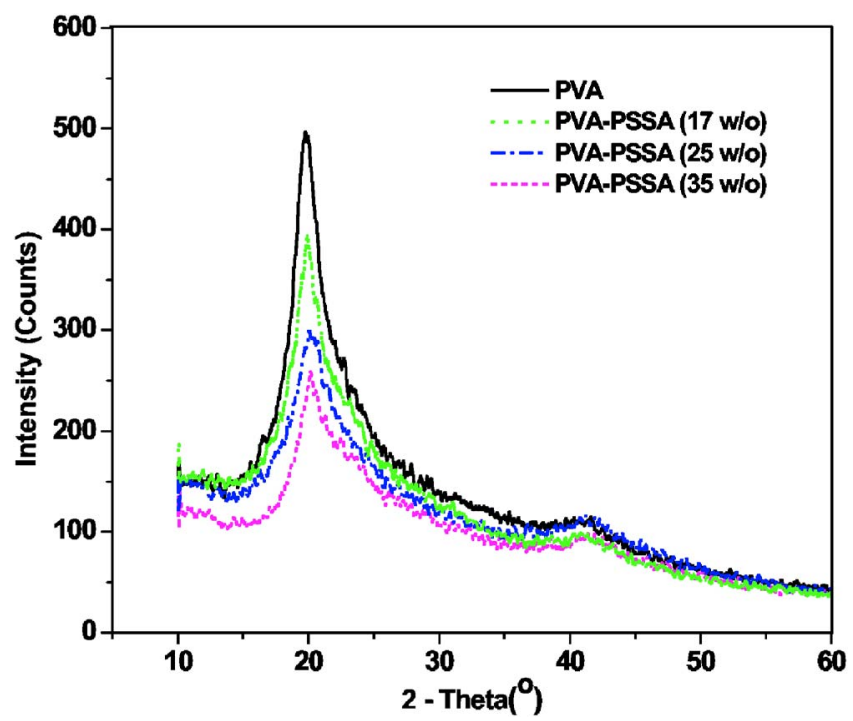

Figure 2. (Color online) XRD profiles for PVA and PVA-PSSA blend membranes. midpoints of ASTM glass-transition temperatures for pristine PVA and PVA-PSSA membranes are at 381.26 and $432.75 \mathrm{~K}$, respec-

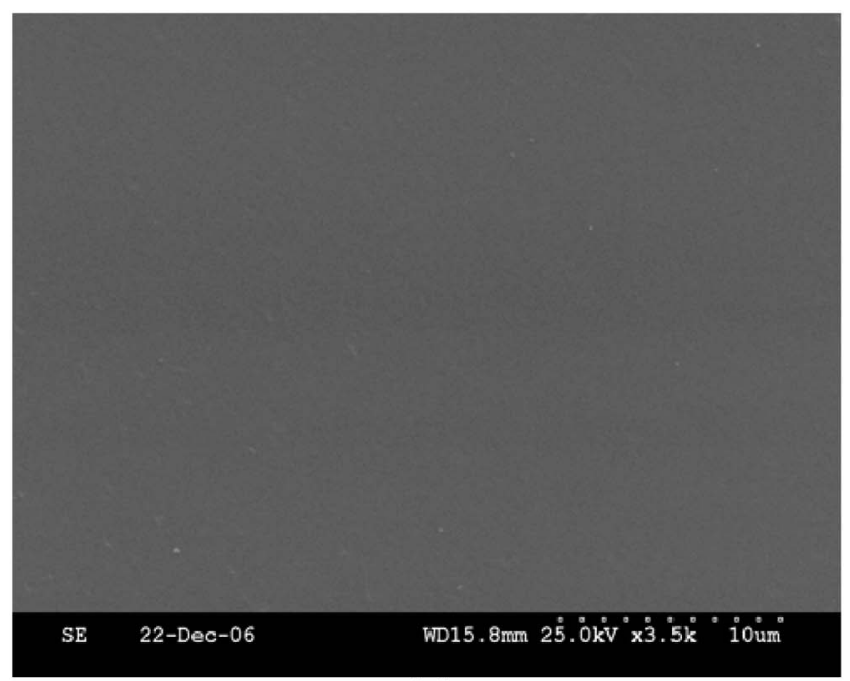

(a)

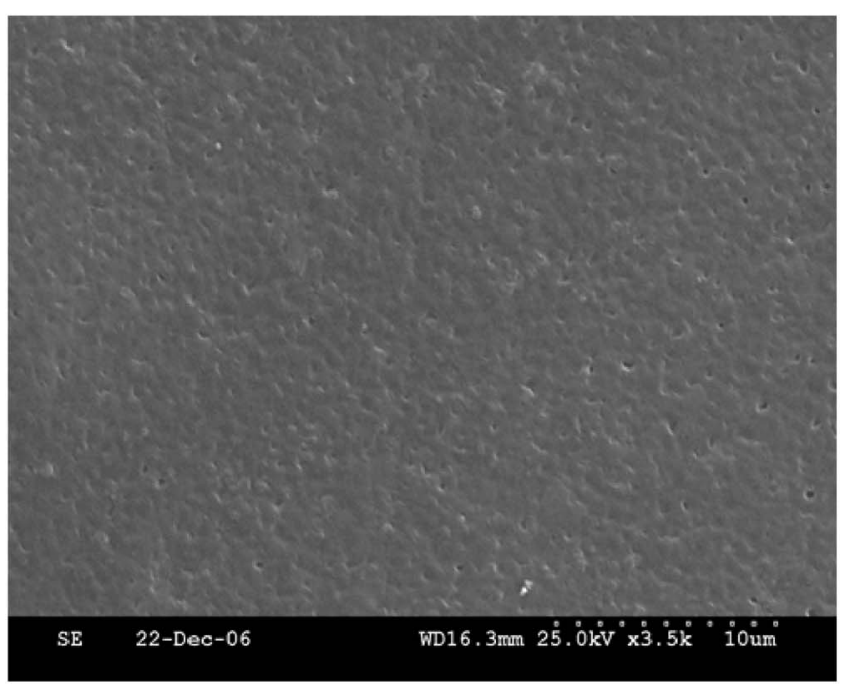

(b)

Figure 3. Typical SEM images for PVA and PVA-PSSA blend membrane. 


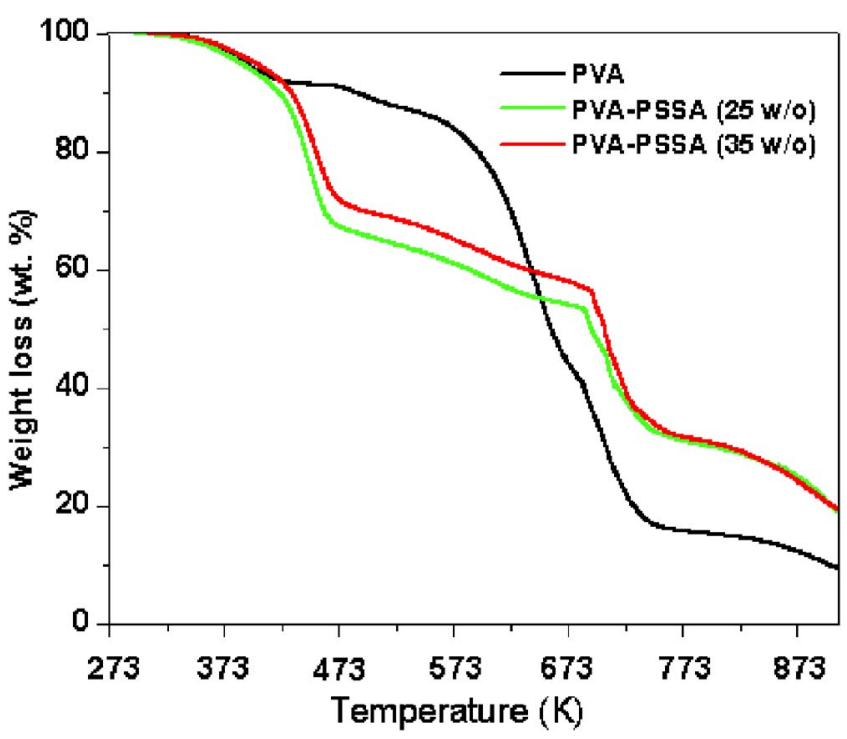

Figure 4. (Color online) TGA thermograms for PVA and PVA-PSSA blend membranes.

tively. In the literature, a $T_{\mathrm{g}}$ value of $398 \mathrm{~K}$ is reported for Nafion membrane. A higher $T_{\mathrm{g}}$ value for PVA-PSSA suggests a higher range of temperature stability and compatibility for MEA fabrication and their use in DMFCs. A single $\left(T_{\mathrm{g}}\right)$ value indicates a homogeneous and compatible single-phase blend membrane. Accordingly, PVA-PSSA blend membranes are truly poly blended.

Mechanical characteristics of membrane.- Figure 6 shows the stress-strain data for PVA and PVA-PSSA blend membrane at $30^{\circ} \mathrm{C}$. On the basis of stress-strain data, it is difficult to identify the onset of the yielding point. Therefore, a proportional limit stress ${ }^{44}$ has been considered to indicate the onset of plastic deformation, and hence the strength. To determine the proportional limit stress, the tangents to the regions on either side of the "bend" are extended up to their intersection. The point of intersection is defined as the proportional limit stress. Young's modulus, which indicates the stiffness of the material, is taken as the linear regression for the initial linear part of the stress-strain curve. The Young's modulus and proportional limit stress of the PVA membrane are 3.24 and $0.977 \mathrm{MPa}$, respectively. In the case of PVA-PSSA blend membrane, the Young's modulus and proportional limit stress are 18.3 and 1.916 $\mathrm{MPa}$, respectively. The high Young's modulus and proportional limit stress values observed for the blend membrane suggest a high strength and stiffness for the blend membrane in relation to the pristine PVA membrane. The Young's modulus for the PVA-PSSA blend membrane is also comparable with the value of $15 \mathrm{MPa}$ reported for commercial Nafion membrane. ${ }^{44}$

Proton conductivity and water-uptake study.-Figure 7 shows a plot of the proton conductivity of pristine PVA, PVA-PSSA blend, and Nafion-117 membranes as a function of temperature. The proton conductivity of the pristine PVA membrane increases with temperature and attains a maximum value of $9.4 \times 10^{-4} \mathrm{~S} / \mathrm{cm}$ at $353 \mathrm{~K}$; a decrease in conductivity is observed beyond $353 \mathrm{~K}$. The proton conductivity of the PVA-PSSA blend membrane increases with the PSSA content. It is realized that the proton conductivity for PVA-35 wt \% PSSA is maximum at $373 \mathrm{~K}$, beyond which the conductivity decreases. The proton conductivity behavior for the
PVA-PSSA membrane is similar to commercial Nafion membrane. In general, during the chemical treatment, hydroxyl groups of PVA matrix tend to cross-link with GA to generate a hydrophobic barrier, providing the polymer a stable morphology that prevents the polymer from dissolving in water. Hydrogen bonds between $-\mathrm{OH}$ of PVA and $-\mathrm{SO}_{3} \mathrm{H}$ of PSSA possibly arise due to the decrease in the distance between the polymer chains. Such a physical interaction between the functional groups results in the formation of hydrophilic ionic channels (or microdomains) by the arrangement of hydrophilic polymeric groups that facilitate proton conduction. ${ }^{45}$

All the membrane samples exhibit an Arrhenius-type temperature dependence of proton conductivity, suggesting thermally activated proton conduction. The activation energy, which is the minimum energy required for proton transport, is obtained for each membrane from the slope of Arrhenius plots using the relationship

$$
\sigma=\sigma_{0} e^{-\left(E_{a} / R T\right)}
$$

where $\sigma$ is the proton conductivity (in $\mathrm{S} / \mathrm{cm}$ ), $\sigma_{0}$ is the preexponential factor, $E_{\mathrm{a}}$ is the activation energy (in $\mathrm{kJ} / \mathrm{mol}$ ), $R$ is the universal gas constant $(=8.314 \mathrm{~J} / \mathrm{mol} \mathrm{K})$, and $T$ is the absolute temperature $(\mathrm{K})$.

As proton conductivity is thermally activated, it is obvious to expect a rise in the conductivity with temperature. The decay in the conductivity values above $353 \mathrm{~K}$ observed for PVA membrane suggests dehydration of the membrane. Thus, not only the capacity of water uptake but also the capacity of the membrane to retain water at higher temperatures is seminal for proton conductivity. The $E$ values of PVA-PSSA blend membranes are higher $(10-16 \mathrm{~kJ} / \mathrm{mol})$ than the $E_{\mathrm{a}}$ value $(8.8 \mathrm{~kJ} / \mathrm{mol})$ for pristine PVA membrane. In other words, the $E_{\mathrm{a}}$ for proton conduction increases with the introduction of PSSA moiety into the PVA matrix. This can be explained by the existence of free and bound water content in the membranes. As mentioned above, the ratio of free water to bound water is higher in the PVA membrane than the PVA-PSSA blend membrane. According to the vehicular mechanism, ${ }^{46}$ free water can act as a protoncarrying medium. However, free water evaporates faster than bound water. The proton conductivity of pristine PVA membrane recedes after $353 \mathrm{~K}$ due to the loss of free water (see Fig. 4). PVA-PSSA blend membranes can hold higher water content than the pristine PVA membrane. Thus, in the case of the PVA-PSSA blend membrane, the proton conductivity increases with temperature up to 373 $\mathrm{K}$ owing to good water retention. The decrease in proton conductivity after $373 \mathrm{~K}$ indicates a loss of bound water, which is hydrogen bonded between PVA and PSSA moieties. The aforesaid characteristic of PVA-PSSA blend membranes is also conducive to polymer electrolyte fuel cells operating at elevated temperatures.

The water uptakes for the PVA and PVA-PSSA blend membranes have also been studied; the data are presented in Fig. 8. The water content in blend membranes is higher in relation to the pristine PVA membrane. The water uptake in the PVA-PSSA blend membrane increases with increasing PSSA content, and reaches a maximum at 25 wt $\%$ of PSSA. When the PSSA content exceeds more than 25 wt $\%$ in the blend membrane, the water uptake is found to decrease, possibly due to an increase in the degree of cross-linking that reduces the space for retaining water around sulfonic acid groups.

Measurements on self-diffusion coefficient by NMR.- The data on the apparent self-diffusion coefficient $\left(D_{\text {app }}\right)$ of water in Nafion117, PVA, and PVA-PSSA blend membranes are presented in Table I. It is found that the apparent self-diffusion coefficient $D_{\text {app }}$ of water in all the membranes is about an order of magnitude less than that of free water $\left(2.3 \times 10^{-9} \mathrm{~m}^{2} \mathrm{~s}^{-1}\right)$. The $D_{\text {app }}$ of water in the PVA 


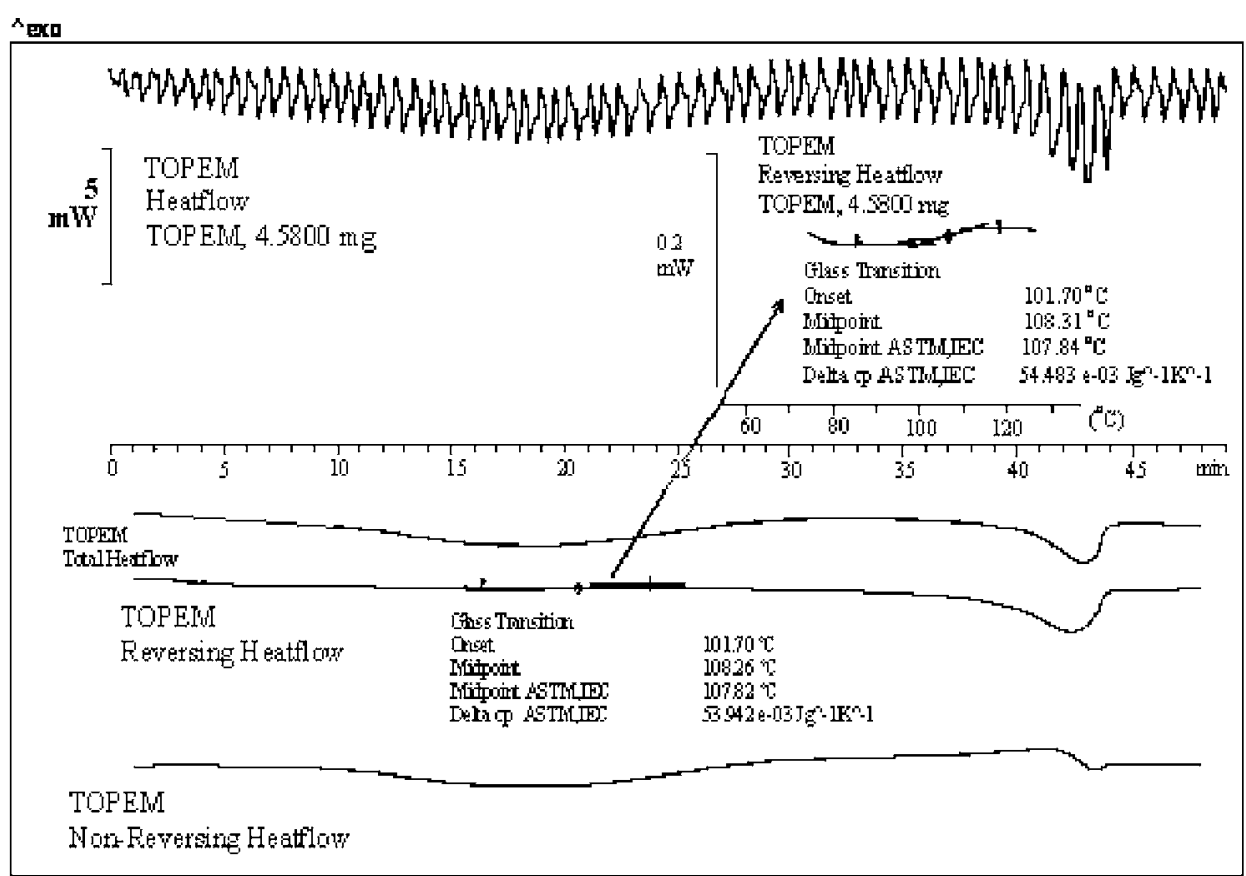

(a)

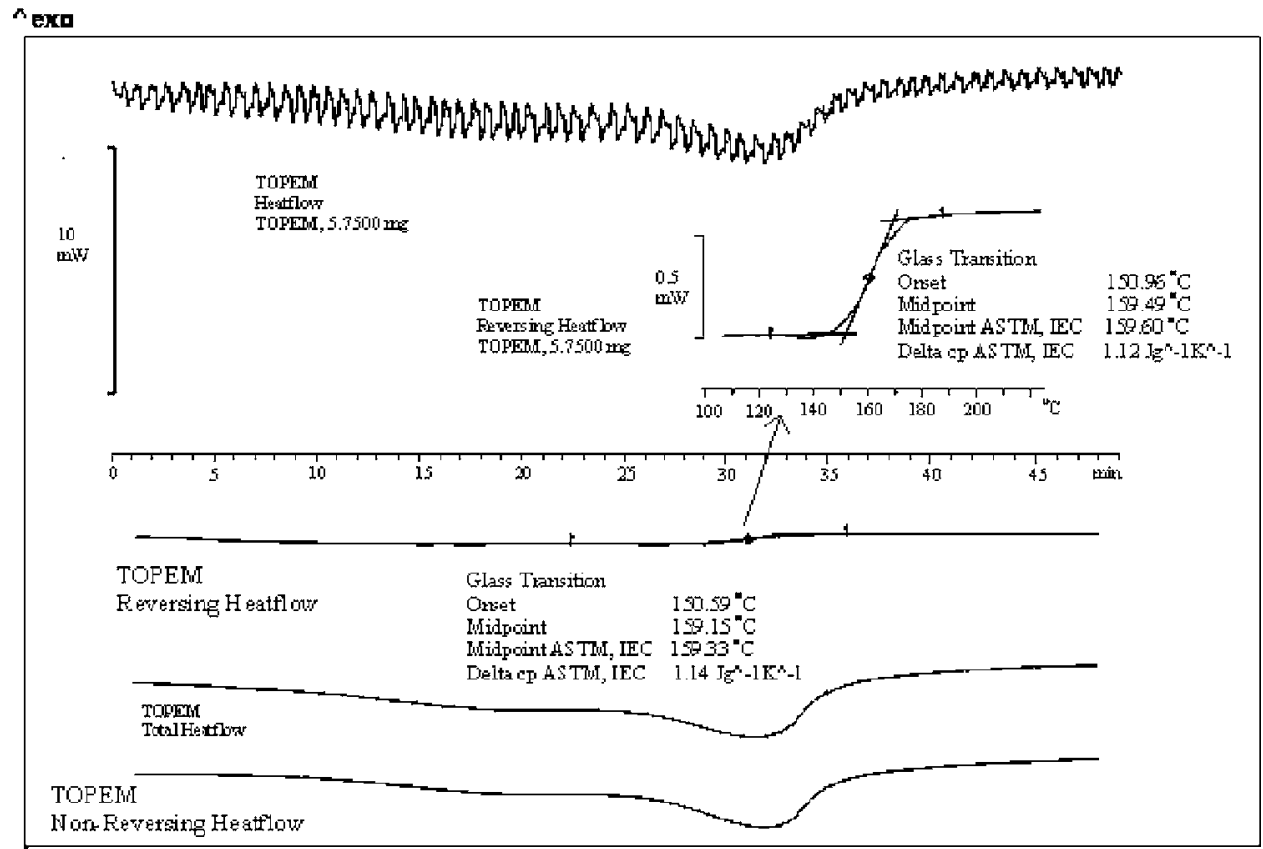

(b)
Figure 5. Typical DSC TOPEM data for (a) PVA and (b) PVA-PSSA blend membrane. membrane is lower than that of water in the PVA-PSSA (25 wt \%) blend membrane, while it is highest for Nafion (6.28 $\times 10^{-10} \mathrm{~m}^{2} \mathrm{~s}^{-1}$ at $\left.\Delta=5.78 \mathrm{~ms}\right)$. Further, the measurement of $D_{\text {app }}$ was performed as a function of the time interval $(\Delta)$ between the two gradient pulses $(\Delta=5.78-70 \mathrm{~ms})$. That the diffusion is restricted, especially in PVA, is demonstrated by the significant decrease of the apparent diffusion coefficient when $\Delta$ increases. The variation of $D_{\text {app }}$ with respect to $\Delta$ is much smaller for the PVAPSSA blend membrane. This mirrors the diffraction results, which show a higher amorphous content in the blend membrane compared to the pristine PVA membrane. It was not possible to measure $D_{\text {app }}$ for Nafion as a function of $\Delta$ because of the significantly increased linewidth of the water signal in this case. ${ }^{\mathrm{d}}$ Accordingly, PVA appears to provide a significantly more restrictive environment for water diffusion as compared to the PVA-PSSA blend membrane.

We have obtained an approximate expression for the apparent diffusion coefficient $D_{\text {app }}$ without invoking the long-time limit [which stipulates $\Delta \gg a^{2} /(2 D)$ ]; it may be shown that when the stipulation for the long-time limit is not met, we have

\footnotetext{
${ }^{\mathrm{d}}$ The estimated apparent spin-spin relaxation time (i.e., $T_{2}^{*}$ ) values of water in Nafion, PVA, and PVA-PSSA blend membranes are $0.64,2.65$, and $1.18 \mathrm{~ms}$, respectively. Here, $T_{2}^{*}$ has been approximated as $(\pi \times \text { linewidth })^{-1}$.
} 


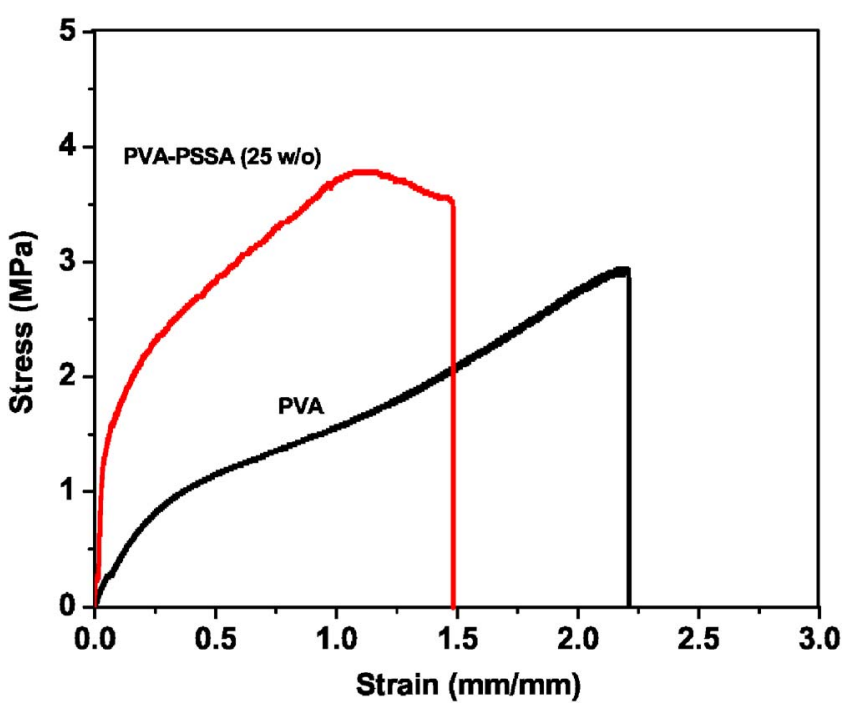

Figure 6. (Color online) Typical stress-strain curves for dry PVA and PVAPSSA blend membrane at ambient conditions.

$$
D_{\text {app }}=\frac{a^{2}}{12 \Delta}\left[1-e^{-\pi^{2} D \Delta / a^{2}}\right]
$$

The standard expression in the long-time limit involves only the first term in square brackets. Employing our expression, the distance scale of the restriction in PVA may be estimated to be $17 \mu \mathrm{m}$, while the real diffusion coefficient amounts to $4.1 \times 10^{-10} \mathrm{~m}^{2} \mathrm{~s}^{-1}$.

Further, ADCs were also obtained at $200 \mathrm{MHz}$ on membrane samples $($ ca. $30 \times 20 \mathrm{~mm}$ ). These data are presented in Table II. These data were obtained by a two- or three-parameter fit of the data obtained from six diffusion weighted images in each case, in accordance with the following equation

$$
I(b)=I(\infty)+[I(0)-I(\infty)] \exp \left(-b D_{\text {app }}\right)
$$

In Eq. $8, I(b)$ is the image intensity for a given value of the diffusion weighting factor $b$, and other symbols have obvious significance. From Table II, the close agreement of these image-based values of $D_{\text {app }}$ obtained at $200 \mathrm{MHz}$ with the self-diffusion measurement results at $500 \mathrm{MHz}$ is noted. ADCs were also measured from diffusion-weighted images at $200 \mathrm{MHz}$ for membranes equilibrated in $2 \mathrm{M} \mathrm{CH}_{3} \mathrm{OH} / \mathrm{H}_{2} \mathrm{O}$ as well as $2 \mathrm{M} \mathrm{CH}_{3} \mathrm{OH} / 99.9 \% \mathrm{D}_{2} \mathrm{O}$. These data are summarized in Table III.

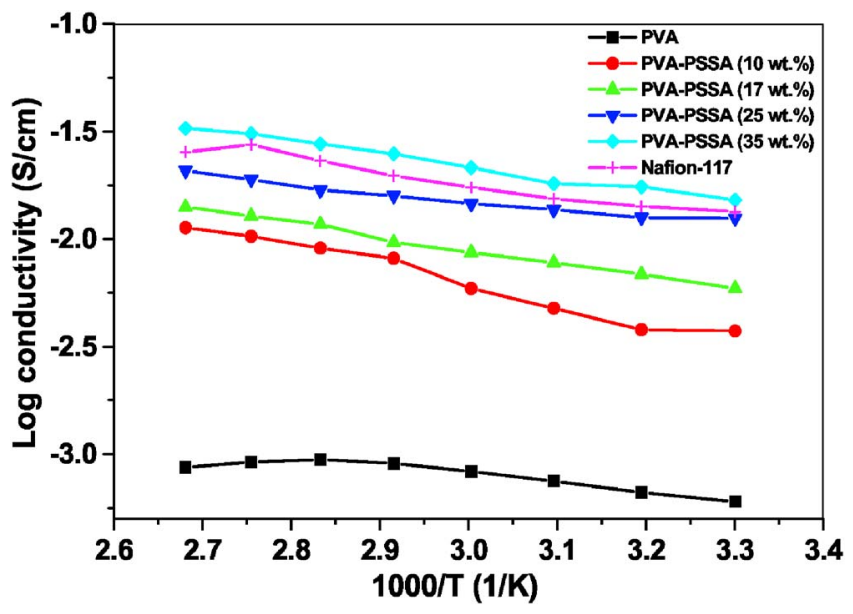

Figure 7. (Color online) Temperature dependence for PVA and PVA-PSSA blend membranes on conductivity.

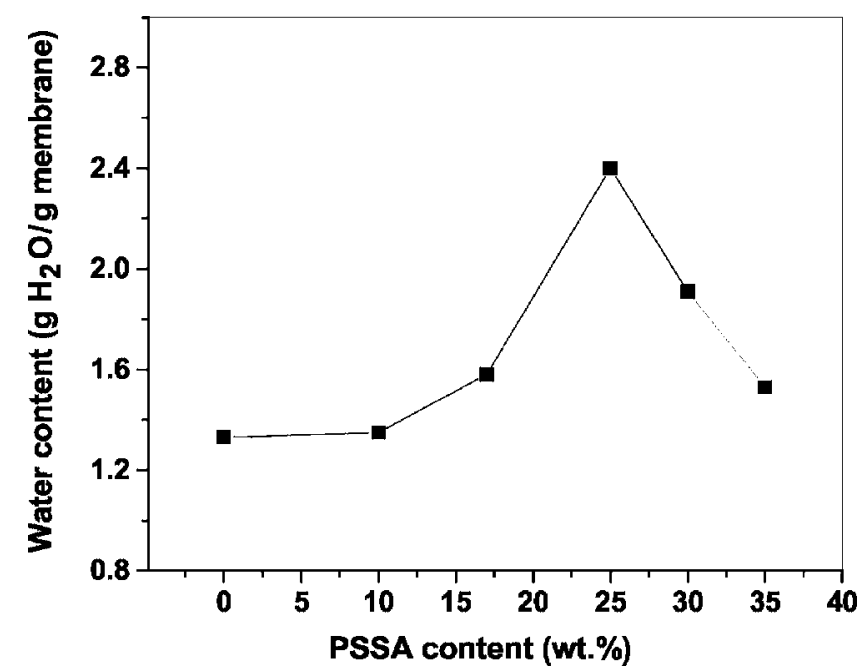

Figure 8. Water uptake results for PVA and PVA-PSSA blend membranes.

Kinetic study involving diffusion of $\mathrm{CH}_{3} \mathrm{OH}$ from membrane ball to $2 \mathrm{MCD} \mathrm{CD}_{3} \mathrm{OD}$ in water.-The diffusion of methanol from Nafion, PVA, and PVA-PSSA (25 wt \%) membrane balls saturated with $2 \mathrm{M} \mathrm{CH}_{3} \mathrm{OH}$ in $\mathrm{D}_{2} \mathrm{O}$ to surrounding $2 \mathrm{M} \mathrm{CD}_{3} \mathrm{OD}$ in water has been recorded at different time intervals by PRESS spectroscopy.

The intensity of the methyl signal in a voxel chosen to lie fully outside the ball was measured as a function of time. The ball had a "diameter" of approximately $8.2 \mathrm{~mm}$. The center of the $4 \mathrm{~mm}$ voxel selected was at a vertical distance $(y)$ of $10.7 \mathrm{~mm}$ from the center of the ball, the other two coordinates ( $x$ and $z$ ) remaining unchanged. Volume localized spectra $(64 \mu \mathrm{L})$ for the three systems are plotted as a function of time in Fig. 9a-c, respectively. These stacked plots clearly demonstrate the clean separation of the methyl peak (of methanol) from the water peak, as well as the efficient suppression of the latter. The kinetics data are culled from the volume localized spectral intensity in the methyl region of the ${ }^{1} \mathrm{H}$ spectra and are presented in Fig. 10a-c, respectively. Equation 9 below is used to fit the curve

$$
I(t)=I(\infty)[1-A \exp (-k t)]
$$

Table IV summarizes the data for the three systems. Methanol release kinetics clearly demonstrates Nafion to exhibit the highest methanol permeability; PVA manifests the lowest, while PVA-PSSA blend has an intermediate permeability value.

Methanol crossover study and performance evaluation of $D M F C$. - Figure 11 shows the cyclic voltammetry curves for methanol oxidation in chamber 2 obtained on platinum electrodes subsequent to methanol crossover across Nafion-117, pristine PVA, and PVA-PSSA blend membranes after $5 \mathrm{~h}$. It is seen that the methanol oxidation limiting current for pristine PVA membrane is $0.49 \mathrm{~mA} / \mathrm{cm}^{2}$, while the methanol oxidation limiting current of Nafion-117 is $0.84 \mathrm{~mA} / \mathrm{cm}^{2}$. The lower methanol oxidation current obtained for the PVA membrane, which is rigid and has fewer pores (due to proper cross-linking of the PVA with GA) restricts the flow of methanol from chamber 1 to chamber 2. Interestingly, little difference is observed between the methanol oxidation peaks for methanol crossover across pristine PVA and PVA-PSSA blend membranes.

Figure 12 compares the polarization curves for MEAs comprising Nafion-117, pristine PVA, and PVA-PSSA blend membranes in DMFCs at $70^{\circ} \mathrm{C}$. A peak power density of $75 \mathrm{~mW} / \mathrm{cm}^{2}$ at a load current density of $250 \mathrm{~mA} / \mathrm{cm}^{2}$ is observed for the DMFC with an MEA comprised of Nafion-117 membrane. The peak power density of about $13 \mathrm{~mW} / \mathrm{cm}^{2}$ at a load current density of $50 \mathrm{~mA} / \mathrm{cm}^{2}$ is 
Table I. Apparent diffusion coefficient of water in PVA, PVA-PSSA, and Nafion membranes from PGSTE measurements with different time intervals $\Delta$ between the gradient pulses $(5.78-70 \mathrm{~ms})$.

\begin{tabular}{|c|c|c|c|c|c|}
\hline \multicolumn{2}{|c|}{ PVA } & \multicolumn{2}{|c|}{ PVA-PSSA (25\%) } & \multicolumn{2}{|c|}{ Nafion } \\
\hline$\Delta(\mathrm{ms})$ & $D \times 10^{10}\left(\mathrm{~m}^{2} \mathrm{~s}^{-1}\right)$ & $\Delta(\mathrm{ms})$ & $D \times 10^{10}\left(\mathrm{~m}^{2} \mathrm{~s}^{-1}\right)$ & $\Delta(\mathrm{ms})$ & $D \times 10^{10}\left(\mathrm{~m}^{2} \mathrm{~s}^{-1}\right)$ \\
\hline 5.78 & 3.53 & 5.78 & 4.35 & 5.78 & 6.28 \\
\hline 20.00 & 2.84 & 20.00 & 4.27 & 20.00 & - \\
\hline 50.00 & 2.34 & 50.00 & 4.28 & 50.00 & - \\
\hline 70.00 & 2.17 & 70.00 & 4.15 & 70.00 & - \\
\hline
\end{tabular}

observed for the DMFC with an MEA comprised of pristine PVA membrane. By contrast, a power density of $90 \mathrm{~mW} / \mathrm{cm}^{2}$ at a load current density of $320 \mathrm{~mA} / \mathrm{cm}^{2}$ is observed for the DMFC with an MEA comprised of PVA-25 wt \% PSSA blend membrane under identical operational conditions. It is obvious that the existence of PSSA, a strong proton-conducting medium in the blend membrane, assists the blend membrane to achieve higher proton conductivity which improves the DMFC performance. Although the methanol crossover across pristine PVA membrane is less than that found across Nafion-117 membrane, we find the performance of the DMFC using pristine PVA membrane to be lower than the performance of the DMFC using Nafion-117 membrane and attribute it to the poor conductivity of PVA and poor adhesion of the membrane with the catalyzed electrodes.

Figure 13 shows the equivalent current for crossed-over methanol across Nafion-117 and PVA-PSSA blend membranes at varying load current densities. The data for the PVA membrane are not shown due to the low operating currents for the cell. Figure 13 shows that the methanol crossover decreases significantly with increasing the load currents for the DMFCs with both the membranes. Interestingly, the PVA-PSSA blend membrane exhibits a lower methanol crossover compared to Nafion membrane. These data further corroborate the ex situ measurement of methanol crossover for different membranes by cyclic voltammometry and NMR.

In practice, the pristine PVA membrane described in this study may encounter a large interfacial resistance owing to the poor adhesion between PVA film and catalyzed electrodes. However, in the case of the blend membrane, the membrane surface roughness helps to increase the adhesion and three-phase contact between electrodes, and the membrane. Accordingly, DMFCs with the PVA-PSSA blend membrane exhibit an improved performance. Moreover, the ease of preparation of PVA-PSSA blend membranes described in this study provides an option to tailor hydrophilic-hydrophobic regions in the membrane.

The cost of the PVA-PSSA blend membrane is about 50 times lower than the Nafion membrane; the former possesses features that enable a higher stability during the cell operation. It is anticipated that the presence of a PVA-rich constituent in the blend membrane

\begin{tabular}{l}
$\begin{array}{l}\text { Table II. Apparent diffusion coefficients of water using diffusion } \\
\text { weighted imaging }(\boldsymbol{\Delta}=\mathbf{5 . 0 3 6} \mathbf{~ m s}) \text {. } \\
\end{array}$ Membrane specification \\
\hline PVA
\end{tabular}
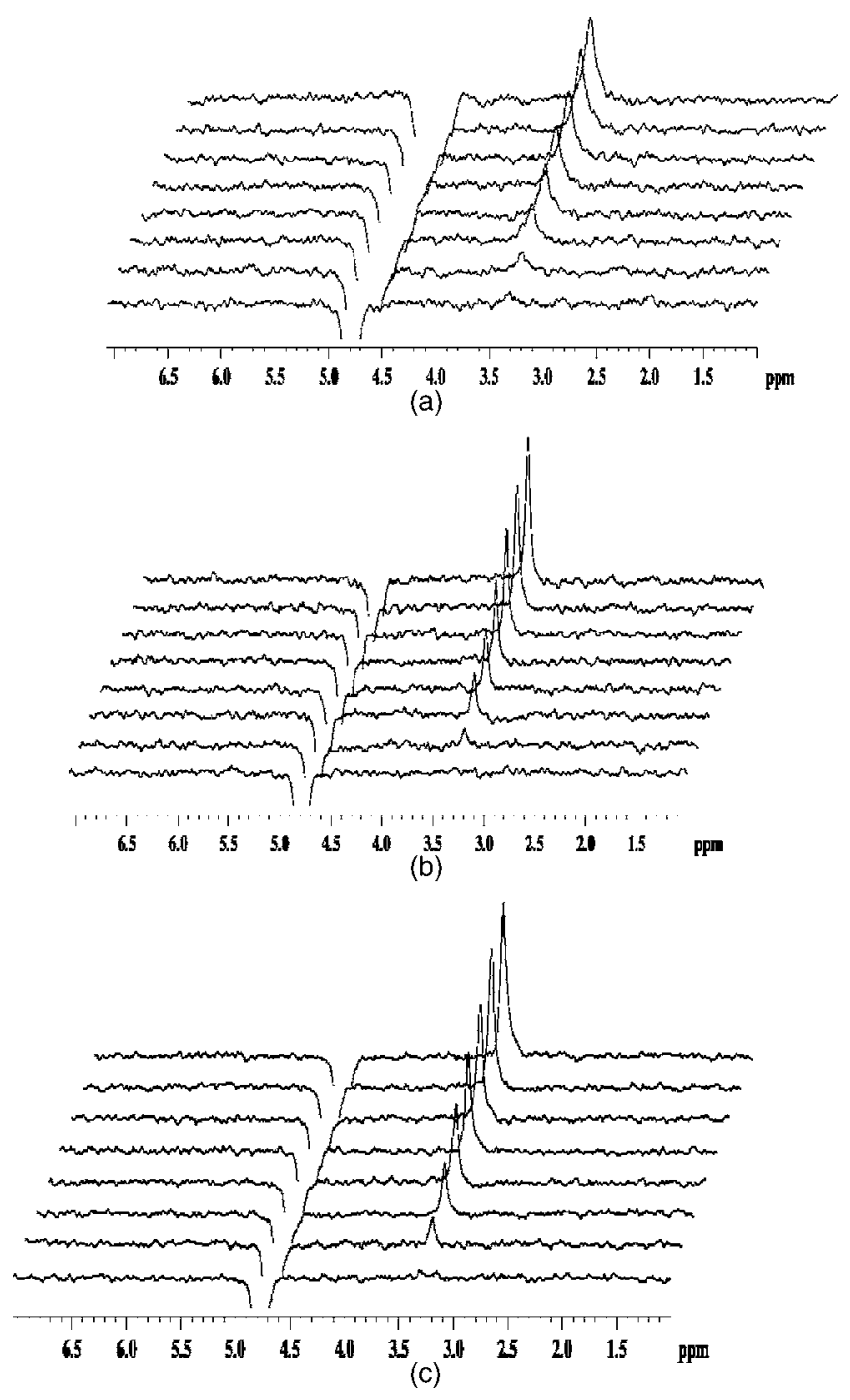

Figure 9. Volume localized spectra of methanol release from balls of (a) Nafion (acquired at 22, 48, 93, 147, 206, 266, 326, and 446 min after dropping the equilibrated ball in the solvent mixture), (b) PVA (acquired at 30 , $71,129,190,249,309,371$, and $460 \mathrm{~min}$ after dropping the equilibrated ball in the solvent mixture), and (c) PVA-PSSA (25 wt \%) (acquired at 13, 54, $95,136,178,215,287$, and 348 min after dropping the equilibrated ball in the solvent mixture). In all the stacked plots, time increases from bottom to top.

Table III. Apparent diffusion coefficients in solvent mixtures using diffusion weighted imaging $(\Delta=5.036 \mathrm{~ms})$.

\begin{tabular}{|c|c|c|c|}
\hline Membrane specification & $\begin{array}{c}D \times 10^{10}\left(\mathrm{~m}^{2} \mathrm{~s}^{-1}\right) \\
\text { Pure water }\end{array}$ & $\begin{array}{l}D \times 10^{10}\left(\mathrm{~m}^{2} \mathrm{~s}^{-1}\right) \\
2 \mathrm{M} \mathrm{MeOH} \text { in } \mathrm{H}_{2} \mathrm{O}\end{array}$ & $\begin{array}{l}D \times 10^{10}\left(\mathrm{~m}^{2} \mathrm{~s}^{-1}\right) \\
2 \mathrm{M} \mathrm{MeOH} \text { in } \mathrm{D}_{2} \mathrm{O}\end{array}$ \\
\hline PVA & 3.78 & 14.7 & 9.67 \\
\hline PVA-PSSA (25 wt \%) & 4.87 & 5.63 & 4.83 \\
\hline Nafion & 7.53 & 7.30 & 5.53 \\
\hline
\end{tabular}




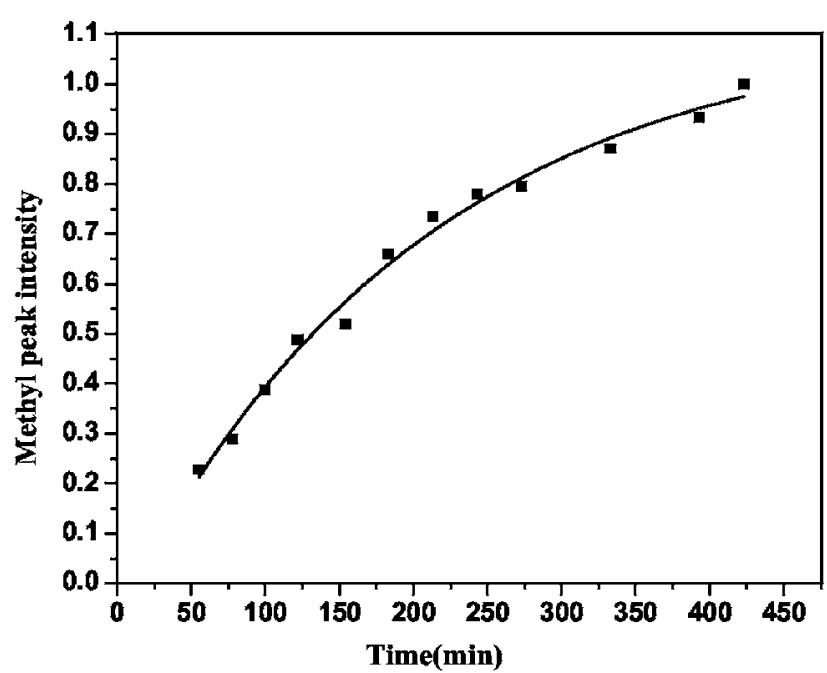

(a)

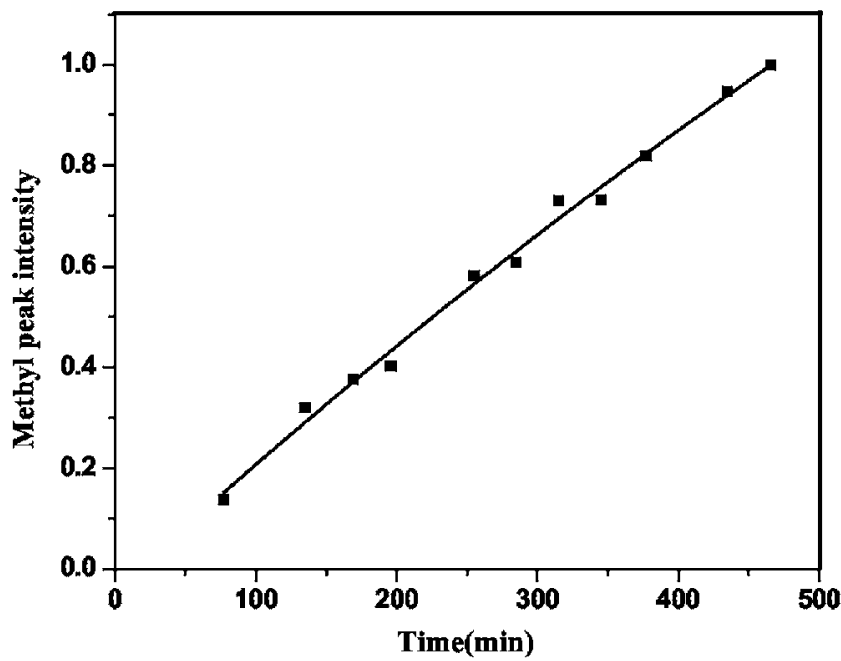

(b)

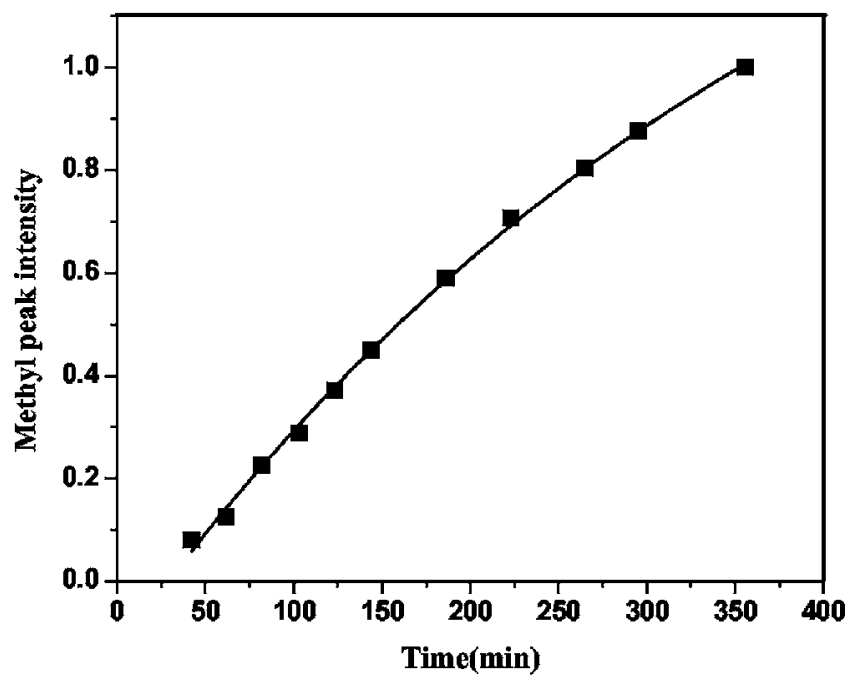

(c)

Figure 10. Integral of methyl signal of methanol vs time for three different membrane balls: (a) Nafion, (b) PVA, and (c) PVA-PSSA (25 wt \%). All the plots were fitted with a first-order exponential equation: $I(t)=I(\infty)[1$ $-A \exp (-k t)]$.

would provide stability to the perceived attack of in situ generated $\mathrm{H}_{2} \mathrm{O}_{2}$ during cell operation by virtue of its known stability against

\begin{tabular}{|c|c|}
\hline Membrane & $k\left(\min ^{-1}\right) \times 10^{3}$ \\
\hline PVA & 0.63 \\
\hline PVA-PSSA (25 wt \%) & 2.47 \\
\hline Nafion & 4.93 \\
\hline
\end{tabular}

peroxide. Moreover, due to the higher water uptake of the blend membrane, the concentration of $\mathrm{H}_{2} \mathrm{O}_{2}$ generated inside the fuel cell during operation is decreased. Added to these features, the wellcross-linked network is expected to reduce the gas crossover during the cell operation, thereby preventing the formation of deleterious radicals that are known to affect the Nafion membranes. ${ }^{47}$ A detailed study on these aspects is currently underway in the authors' laboratory. The aforesaid features, coupled with the demonstrated results reported in this study, make this blend membrane competitive with Nafion membranes.

\section{Conclusions}

One of the challenges in realizing commercially viable DMFCs is to develop a cost-effective substitute to Nafion membranes presently employed with these fuel cells. Toward this endeavor, we have reported here a cost-effective PVA-PSSA membrane exhibiting a high proton conductivity with a reduced methanol permeability, good water retention capacity, and mechanical stability. The mem-

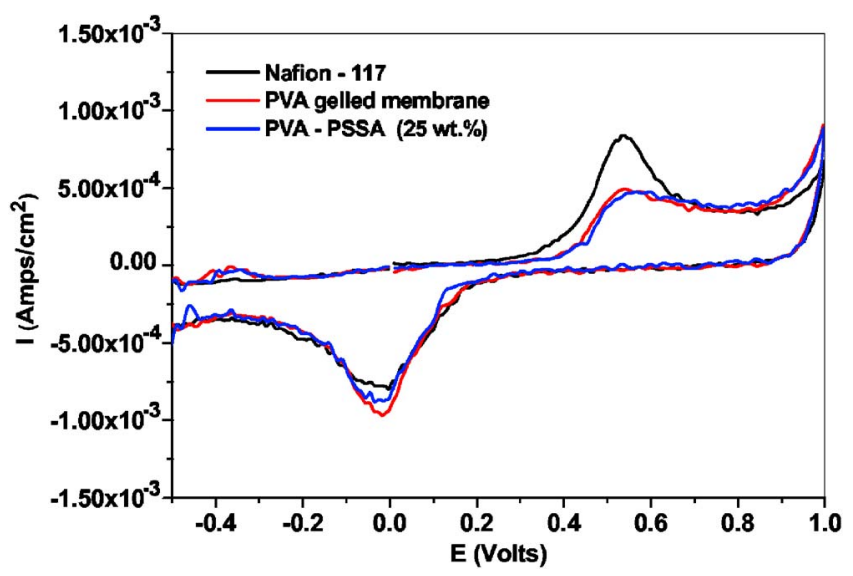

Figure 11. (Color online) CVs for Nafion-117, pristine PVA, and PVAPSSA blend membrane at a scan rate of $100 \mathrm{mV} \mathrm{s}^{-1}$ after $5 \mathrm{~h}$.

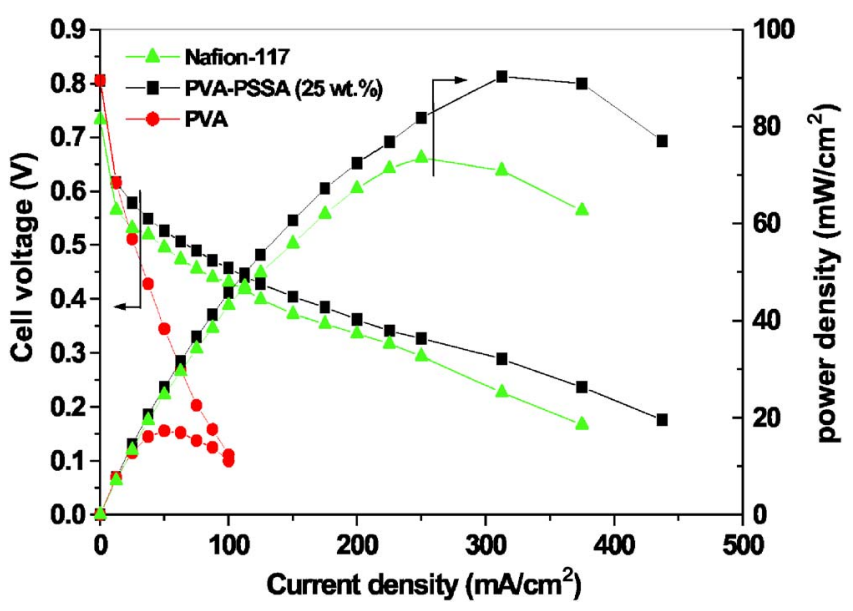

Figure 12. (Color online) Performance curves for DMFCs with Nafion-117, pristine PVA, and PVA-PSSA blend membranes at $70^{\circ} \mathrm{C}$ using aqueous methanol and oxygen reactants at atmospheric pressure. 


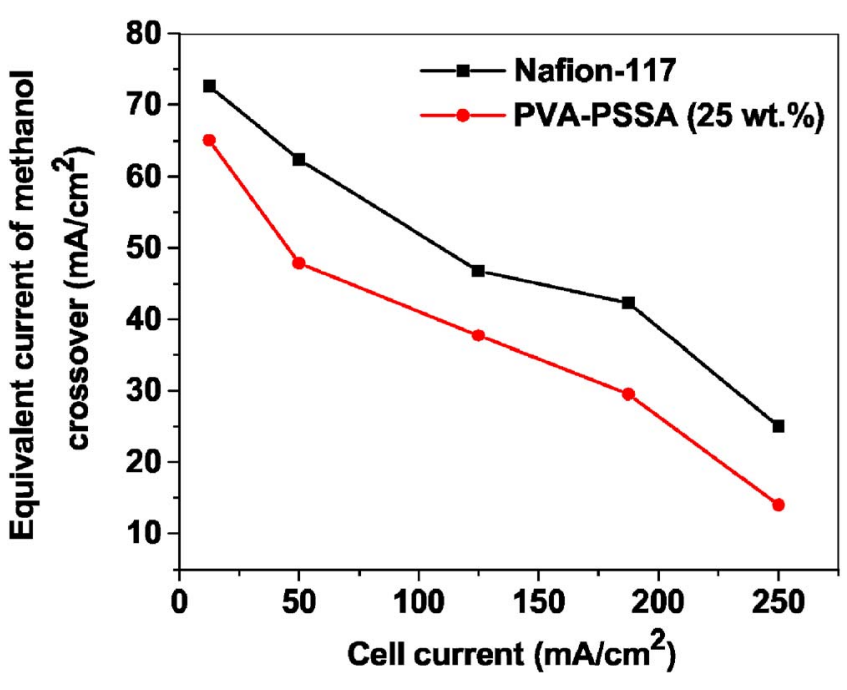

Figure 13. (Color online) Equivalent current of methanol crossover through Nafion-117 membrane and PVA-PSSA (25 wt \%) membrane from anode to cathode in a $\mathrm{MeOH} / \mathrm{O}_{2}$ single cell at $70^{\circ} \mathrm{C}$.

brane has shown effective utility in a DMFC fueled by aqueous methanol. Spatially resolved NMR has been found to be especially useful in designing the PVA-PSSA membrane for application in fuel cells.

\section{Acknowledgments}

This study was carried out under the New Millennium Indian Technology Leadership Initiative (NMITLI) program of CSIR, New Delhi. We thank R. A. Mashelkar, FRS for his constant encouragement and support. N.N. and A.B. thank IIT Madras and CSIR, respectively, for the fellowship. N.C. thanks DST and IIT Madras for MRM and MRI system grants.

Indian Institute of Science assisted in meeting the publication costs of this article.

\section{References}

1. X. Ren, M. S. Wilson, and S. Gottesfeld, J. Electrochem. Soc., 143, L12 (1996).

2. K. W. Boddeker, K. V. Peinemann, and S. P. Nunes, J. Membr. Sci., 185, 1 (2001).

3. K. D. Kreuer, J. Membr. Sci., 185, 29 (2001).

4. K. Scott, W. M. Taama, P. Argyropoulos, and K. Sundmacher, J. Power Sources, 83, 204 (1999).

5. M. K. Ravikumar and A. K. Shukla, J. Electrochem. Soc., 143, 2601 (1996).

6. S. Surampudi, S. R. Narayanan, E. Vamos, H. Frank, G. Halpert, A. LaConti, J. Kosek, G. K. Surya Prakash, and G. A. Olah, J. Power Sources, 47, 377 (1994).

7. V. Tricoli, N. Carretta, and M. Bartolozzi, J. Electrochem. Soc., 147, 1286 (2000).

8. M. K. Song, S. B. Park, Y. T. Kim, K. H. Kim, S. K. Min, and H. W. Rhee, Electrochim. Acta, 50, 639 (2004).
9. S. Panero, P. Fiorenza, M. A. Navarra, J. Romanowska, and B. Scrosati, J. Electrochem. Soc., 152, A2400 (2005).

10. L. C. Klein, Y. Daiko, M. Aparicio, and F. Damay, Polymer, 46, 4504 (2005)

11. J. M. Song, N. Asano, K. Miyatake, H. Uchida, and M. Watanabe, Chem. Lett., 34, 996 (2005).

12. J. M. Song, K. Miyatake, H. Uchida, and M. Watanabe, Electrochim. Acta, 51, 4497 (2006).

13. N. Miyake, J. S. Wainright, and R. F. Savinell, J. Electrochem. Soc., 148, A898 (2001).

14. Z. Liu, B. Guo, J. Huang, L. H. Ong, M. Han, and L. M. Gan, J. Power Sources, 157, 207 (2006)

15. V. Baglio, A. S. Aricò, A. D. Blasi, V. Antonucci, P. L. Antonucci, S. Licoccia, E. Traversa, and F. S. Fiory, Electrochim. Acta, 50, 1241 (2005).

16. A. K. Sahu, G. Selvarani, S. Pitchumani, P. Sridhar, and A. K. Shukla, J. Electrochem. Soc., 154, B123 (2007).

17. S. Y. Kim, H. S. Shin, Y. M. Lee, and C. N. Jeong, J. Appl. Polym. Sci., 73, 1675 (1999).

18. N. A. Choudhury, A. K. Shukla, S. Sampath, and S. Pitchumani, J. Electrochem. Soc., 153, A614 (2006).

19. J. F. Blanco, Q. T. Nguyen, and P. Schaetzel, J. Membr. Sci., 186, 267 (2001).

20. H. B. Park, S. Y. Nam, J. W. Rhim, J. M. Lee, S. E. Kim, J. R. Kim, and Y. M. Lee, J. Appl. Polym. Sci., 86, 2611 (2002).

21. C. S. Wu, F. Y. Lin, C. Y. Chen, and P. P. Chu, J. Power Sources, 160, 1204 (2006).

22. L. Li, L. Xu, and Y. Wang, Mater. Lett., 57, 1406 (2003).

23. W. Xu, C. Liu, X. Xue, Y. Su, Y. Lv, W. Xing, and T. Lu, Solid State Ionics, 171, 121 (2004)

24. J. W. Rhim, H. B. Park, C. S. Lee, J. H. Jun, D. S. Kim, and Y. M. Lee, J. Membr Sci., 238, 143 (2004).

25. D. S. Kim, H. B. Park, J. W. Rhim, and Y. M. Lee, J. Membr. Sci., 240, 37 (2004).

26. G. M. Wu, S. J. Lin, and C. C. Yang, J. Membr. Sci., 275, 127 (2006).

27. D. S. Kim, M. D. Guiver, S. Y. Nam, T. Yun, M. Y. Seo, S. J. Kim, H. S. Hwang, and J. W. Rhim, J. Membr. Sci., 281, 156 (2006).

28. A. Lewandowski, K. Skorapaka, and J. Malinska, Solid State Ionics, 133, 265 (2000).

29. R. A. Vargas, V. H. Zapata, E. Matallana, and M. A. Vargas, Electrochim. Acta, 46, 1699 (2001).

30. J. W. Rhim, H. S. Hwang, D. S. Kim, H. B. Park, C. H. Lee, Y. M. Lee, G. Y. Moon, and S. Y. Nam, Macromol. Res., 13, 135 (2005).

31. M. S. Kang, J. H. Kim, J. Won, S. H. Moon, and Y. S. Kang, J. Membr. Sci., 247, 127 (2005).

32. A. M. Araujo, M. T. Neves, W. M. Azevedo, G. G. Oliveira, D. L. Ferreira, R. A. L. Coelho, E. A. P. Figueiredo, and L. B. Carvalho, Biotechnol. Tech., 11, 67 (1997).

33. J. Qiao, T. Hamaya, and T. Okada, J. Mater. Chem., 15, 4414 (2005).

34. J. Kawamura, K. Hattori, T. Hongo, Y. Asayama, N. Kuwata, T. Hattori, and J. Mizusaki, Solid State Ionics, 176, 2451 (2005).

35. A. K. Sahu, G. Selvarani, S. Pitchumani, P. Sridhar, and A. K. Shukla, Indian Pat. 1831DEL2007 (submitted).

36. J. E. Tanner, J. Chem. Phys., 52, 2523 (1970).

37. D. Le Bihan, Magn. Reson. Q., 7, 1 (1999).

38. E. O. Stejskal and J. E. Tanner, J. Chem. Phys, 42, 288 (1965).

39. J. Granot, J. Magn. Reson. (1969-1992), 70, 488 (1986).

40. P. A. Bottomley, Ann. N.Y. Acad. Sci., 508, 333 (1987).

41. R. Jiang and D. Chu, J. Electrochem. Soc., 151, A69 (2004).

42. N. Vassal, E. Salmon, and J. F. Fauvarque, Electrochim. Acta, 45, 1527 (2000).

43. B. J. Holland and J. N. Hay, Polymer, 42, 6775 (2001).

44. Y. Tang, A. M. Karlsson, M. H. Santare, M. Gilbert, S. Cleghorn, and W. B. Johnson, Mater. Sci. Eng., A425, 297 (2006).

45. M. S. Kang, Y. J. Choi, and S. H. Moon, J. Membr. Sci., 207, 157 (2002).

46. D. S. Kim, H. B. Park, J. W. Rhim, and Y. M. Lee, J. Membr. Sci., 240, 37 (2004).

47. M. Inaba, T. Kinumoto, M. Kiriake, R. Umebayashi, A. Tasaka, and Z. Ogumi, Electrochim. Acta, 51, 5746 (2006). 